

\title{
Creative Marketing as an effective way to attract customers- Marketing creativo como una forma efectiva de atraer clientes
}

\author{
By Sol A. Rodriguez R. - Angel F. Martinez T \\ Peoples' Friendship University of Russia, RUDN University \\ Moscow, Russia.
}

\begin{abstract}
The article studies the ways in which creative marketing and a brilliant idea can drive sales of a product or make it fail. Creating emotional bonds with consumers is one of the best strategies that can used to reach the public and make them buy the advertised item, you just need to see the problem and offer a solution.
\end{abstract}

Keywords: Marketing, Creativity, Customers / Marketing, Creatividad, Compradores 
En el contexto de una mayor competencia entre los fabricantes, aumenta el trabajo de los vendedores y las agencias de publicidad. El marketing creativo se enfoca en desarrollar métodos para generar engagement con los consumidores, a un nivel emocional, tener la capacidad de interesar al consumidor, atraer su atención, provocarle el deseo de ir y comprar el producto anunciado.

Las empresas, con ayuda de los agentes, crean los canales para así comunicarse con sus consumidores, haciéndolos hablar de su producto a los demás. Las ideas creativas en la publicidad ayudan a promocionar el producto, haciéndolo más interesante para audiencias. El agente de publicidad y comercializador estadounidense Joseph Sugerman dice: "que incluso si ha estudiado a sus consumidores, los entiende, entiende su producto, necesita conciencia de algo más [1, P. 41]"1.

Para mostrar un producto al público consumidor, es necesario los agentes cumplan previamente con las necesidades y solicitudes de la compañia para la cual están diseñando. Un ejemplo es la compañía de cigarrillos "Philip Morris International", en su momento de introducir en el mercado de su nueva marca "Parliament" a primera vista actuó correctamente; Esta marca de nuevos cigarrillos se presentó al público con una característica distintiva y diferente a los demás, los cigarros tenían un nuevo y exclusivo filtro, aparte de un precio más bajo y accesible que el de su mayor competencia Marlboro, marca que anteriormente también pertenecía a Philip Morris International.

Sin embargo, las ventas en realidad mostraron un resultado modesto y no satisfactorio. Los vendedores de la compañía descubrieron que en ese rango de precio, había varios productos que tenían una gran cantidad de ofertas, y el consumidor hizo la elección a favor de una marca familiar que conocía bien.

\footnotetext{
- ${ }^{1}$ Sugerman J (2006). The adweek of copywriting handbook - Wiley; Edition: 1 - 41
} 
La exclusividad del filtro para el consumidor no resulto atractivo. La compañía retiro por un año la marca "Parliament" del mercado, para luego volver con una nueva estrategia, tomar la decisión de aumentar el precio y promocionar el producto a targets más altos.

\section{Albert Lasker el hombre que se cree que más ha ganado en la historia de publicidad.}

En 1890, gracias al uso de nuevas técnicas en el cultivo de naranjas en California, aumento drásticamente la cosecha de naranjas, sin embargo la demanda del producto no era tan grande, las principales empresas productoras de naranjas decidieron agruparse en una cooperativa llamada "Sunkist". Sin embargo, incluso este movimiento no solucionó el problema de las ventas: la cosecha fue tanto y aumentó cada año, que los productores no tuvieron tiempo de encontrar nuevos mercados.

Cooperativa decidió atraer a la agencia "L\&T" en donde trabajaba Albert Lasker para hacer la publicidad de naranjas. La tarea asignada a la agencia de publicidad fue la siguiente: en poco tiempo aumentar drásticamente las ventas de naranjas.

Lasker en su anuncio sugirió beber jugo de naranja por la mañana, sabía que la naranja era rica en vitamina $\mathrm{C}$ y explicando en un anuncio lo saludable que era, convirtió el jugo de naranja en algo más que un símbolo del estilo de vida americano, pues lo convirtió también un sinónimo de una persona exitosa, familiar, rica extendiéndose mucho más allá del país. Lasker no solo pudo lograr la atención de los consumidores, si no que creó de esto un ritual obligatorio para comenzar el día.

En el camino hacia el éxito, se cometen errores, hay fracasos, se toman decisiones equivocadas.

Las marcas más grandes del mundo que han logrado ser reconocidos a nivel internacional: The Coca-cola Company, Nestle, Mcdonals, entre otras, saben que una decisión puede crear 
un problema, o solucionar una situación. Lo importante es darse cuenta del problema y girar la situación actual a su favor.

\section{Marketing de confrontación}

Confrontación como la de empresas "The Coca-Cola Company" y "PepsiCo" se han convertido en un verdadero arte de publicidad, que incluye varios tutoriales de marketing.

Los vendedores de las empresas han creado muchas acciones creativas. Sucedía que "PepsiCo" siempre estaba rezagada y tenía que atacar a su competidor, crear ataques exitosos y efectivos.

La publicidad "The Coca-Cola Company" siempre se ha basado en los valores tradicionales y en sus promociones, hace hincapié en las vacaciones, la amistad y la familia.

A su vez, la empresa "PepsiCo" se apoyó y puso énfasis en el público juvenil. Si "The CocaCola Company" usó activamente a Santa Claus en sus promociones navideñas, "PepsiCo" invita a anunciar su producto a las estrellas de cine, música y deportes del momento. La esfera de influencia entre las dos compañías está muy dividida, sin embargo esa división es lo que permite números en ventas tan exitosos.

Las campañas iniciales de la marca de sartenes "Tefal", hacían hincapié en sus promociones en el hecho de que al cocinar no era necesario usar aceite, comidas más saludables, por esto se creía que sus sartenes se vendían. Sin embargo, más tarde resultó que la comida al prepararse no se quemaba en sus sartenes y es por eso que se venden. Sus campañas han cambiado rápidamente el contenido de la publicidad, lo que lo ha aumentado significativamente la eficacia de sus ventas.

Se puede dar un ejemplo nacional de publicidad al hablar de la cadena de comida rápida venezolana Pollos Arturo’s, creada en 1985 por el inmigrante guatemalteco Arturo Gutiérrez. 
La decisión de iniciar un nuevo concepto en los restaurantes, integrando los sistemas de administración de las grandes compañías como: Mcdonals, KFC o Wendy’s, pero guiándose por el amor de los venezolanos por el pollo; fue una idea brillante. Usando un simple slogan “Come de verdad, come en Arturo's”, y un menú simple basado en: pollo, ensaladas, papas.

Por lo tanto al establecer un vínculo entre la empresa y el consumidor, se ayuda a desarrollar el producto y gracias a esto poco a poco la marca ha ido creciendo, abriendo sucursales a nivel nacional y en 2019 por primera vez a nivel internacional, ubicando un restaurant en Madrid, España.

El marketing creativo ayuda no solo a promocionar el producto en el mercado, sino también a crear una idea brillante, una imagen memorable a la que se atraerá el consumidor, por la cual se crea publicidad.

\section{Bibliography:}

1) Sugerman J. (2006). The Adweek of copywriting handbook: The ultimate guide to writing powerful advertising and marketing copy from one of America's top Copywriters - Wiley; (1) - 41

2) Equipo de Tutores Deusto Formación (2013). Las claves del Marketing Creativo Blog de Marketing digital.

Recuperado desde: https://www.deustoformacion.com/blog/marketingdigital/claves-marketing-creativo

3) Pimentel S. (2016). Marketing creativo vs. marketing de investigación. Netcomerce. Recuperado desde:/https://info.netcommerce.mx/blog/marketingcreativo-vs-marketing-de-investigacion/

4) Lesley P. (2015). La Compañía - Blogspot. Recuperado desde: http://arturosabrocitoelmejordetodos.blogspot.com/

5) Arturo web site (2016). Nuestro fundador - Video. Recuperado desde: https://youtu.be/Z96vsI71qNg 


\section{About the author}

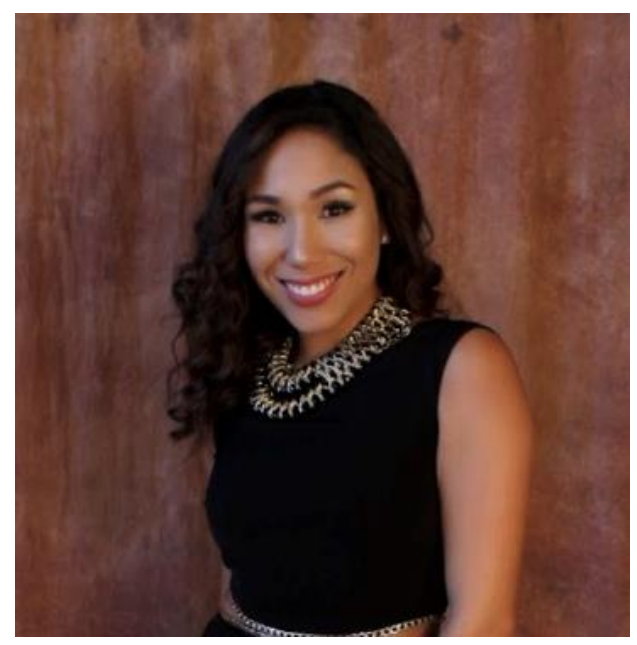

Born in Caracas - Venezuela, Sol Rodriguez is an architect of José María Vargas University, with a Master's degree in Residential, public and industrial architecture from RUDN University in the Russian Federation. With experience in construction supervision and interior design. 